\title{
Mandarin Chinese Tonal Acquisition by Thai Speakers
}

\author{
Apichai Rungruang ${ }^{1} \&$ Yanhong $\mathrm{Mu}^{2}$ \\ ${ }^{1}$ Faculty of Humanities, Naresuan University, Phitsanulok, Thailand \\ ${ }^{2}$ Naresuan University International College, Phitsanulok, Thailand \\ Correspondence: Apichai Rungruang, Faculty of Humanities, Naresuan University, Tha Pho Sub-district, \\ Amphoe Mueang, Phitsanulok 65000, Thailand. E-mail: rapichai2002@yahoo.com
}

Received: March 2, 2017

Accepted: March 8, 2017

Online Published: April 19, 2017

doi:10.5539/ass.v13n5p107

URL: https://doi.org/10.5539/ass.v13n5p107

\begin{abstract}
The aim of the present empirical study is two-fold. The first aim is to investigate why Thai university students perceive a certain tone better than others or why a certain tone is more difficult to perceive than others. The second aim is to examine to what extent Thai university students can perceive four Chinese Mandarin tones. 14 volunteer university students ( 2 males; 12 females) participated in the study. Research tools were structured interview and the perception test. The findings from the interview reveal that 9 out of $14(64 \%)$ students claimed that tone 4 was the easiest tone either to perceive or produce. In contrast, 10 out of $14(71 \%)$ stated that tone 3 was the most difficult one to perceive. The qualitative data findings from the interview were greatly consistent with the quantitative data ones from the perception test. That is, Thai speakers performed well in tone 4 (mean scores 24.92 or $99.68 \%)$ and tone $1(24.35$ or $97.40 \%)$. On the other end of the scale, they had some difficulty identifying tone $2(21.42$ or $85.68 \%)$ and tone $3(19.50$ or $78 \%)$. It can be concluded that firstly, the hierarchy of tone accessibility from the least difficult to the most difficult one was tone $4>$ tone $1>$ tone $2>$ tone 3 . Secondly, students' native language (Thai) or L1 plays a crucial role to their tonal acquisition when Thai speakers deal with foreign lexical tones. For one important reason, tones 1 and 4 in Chinese are very similar to the mid tone and the falling tone in Thai, respectively.
\end{abstract}

Keywords: Chinese tone, Thai speakers, tone perception

\section{Introduction}

\subsection{Introduce the Problem}

At the beginning of the twenty-first century, Chinese courses are available in universities, colleges, secondary schools, or weekend school, no matter which continent one goes to. 506 public universities have Chinese language programs in North America. In Europe, particularly in France, 152 universities offer Chinese courses. In Australia, Chinese was available at 29 universities in 2001. In Asia, South Korea has the highest number of students (approximately over a hundred thousand students) who learn Chinese as a foreign language (CFL) (Xing, 2006). In Thailand, the Chinese language plays an increasingly important role, and the number of Thai students has taken Chinese language courses three times over the past 5 years. Theerawongseri (2009), a former Thai diplomat at Guangzhou, claimed that over 10 Confucian Institutes were set up in many Thai universities to promote Chinese language and culture. These Confucian institutes in Thai public universities also provided Chinese courses to serve the high demand in their areas. Nonetheless, what a former Thai Consul-General mentions is compatible with what Masuntisuk (2009) - a researcher from Chinese Studies Center, Institute of Asian Studies, Chulalongkorn University - states in that the high demand for Chinese comes with many problems, namely the lack of Chinese teachers, inappropriateness of the textbooks, ineffectiveness of the teaching methodology and learning, and so on. Furthermore, the researchers found that not much research on Chinese language teaching and learning, particularly how Thai people deal with the Mandarin Chinese sound system (consonants, vowels, and tones) has been conducted. In terms of Chinese tonal acquisition by Thai speakers, surprisingly, only two research studies by Chen (2012), conducted in Taiwan, and Li (2016), conducted in the People's Republic of China, were found, but they suggested different research findings. That is, Chen ranked the level of tonal difficulty from low to high level: tone $1>$ tone $4>$ tone $3>$ tone 2 . Thus, Thai speakers performed best in tone 1 and had some difficulty coping with tone 2 . On the other hand, Li's study illustrates a different hierarchy of tonal accessibility: tone $4>$ tone $1>$ tone $2>$ tone 3 . Tone 4 outperformed the other three 
tones; tone 3 reflected the poorest performance. Both studies were conducted in native Chinese speaking countries where Chinese was regarded as a second language (CSL). As a result, the present study on Mandarin Chinese tonal acquisition by Thai speakers is not only to provide more research studies on Chinese language study, but also to paint a picture of what Thai speakers who learn Chinese as a foreign language (CFL) are facing and how they cope with Chinese tones, specifically the tones that do not exist in Thai phonological system. In addition, the findings can help future research to set up teaching approaches to improve Thai learners' tone acquisition as well.

\subsection{Four Mandarin Chinese Tones}

Before moving forward to the present study, a brief summary of Chinese tones should be made. By and large, Chinese has four major tones (Chen, 1997; Chen, 2012; Hallé, P., Chang, Y. \& Best, C., 2004; Lin, 2007; Li, 2016; Miracle, 1989; and Xing, 2006). The first tone shows high flat pitch level (with pitch value 55). The second tone is high rising (35). The third one reveals a pitch contour from low falling-rising (214). Notice that the second and the third tone end with a rising pitch, but the second tone starts at the middle point on the pitch scale of tone. The third tone starts dip to the lowest pitch on the scale (Xing, 2006). The final tone reflects high falling (51). Below are four Chinese tones spoken by a native Mandarin Chinese female speaker. Each tone on the syllable $/ \mathrm{ma} /$ represents a different lexical item.

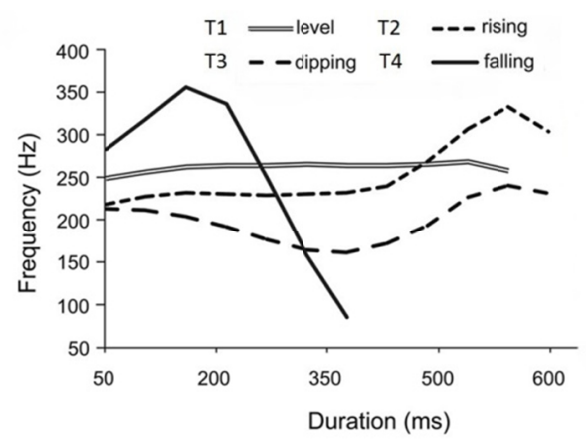

Figure 1. Classification of Four Mandarin Chinese Tones

Source: Tillmann et al (2011).

\subsection{Research Objectives}

1. To investigate the reasons why Thai university students perceive a certain tone better than others.

2. To examine how Thai university students perceive the four Chinese Mandarin tones.

\subsection{Research Questions}

1. Why do Thai university students perceive a certain tone better than others?

2. To what extent can Thai university students perceive the four Chinese Mandarin tones?

\section{Method}

\subsection{Participants}

14 second year students from a Thai university volunteered to participate in the present study ( 12 female students; 2 male students). All of them had registered for Chinese I in the first semester of academic year 2015 and were taking Chinese II at the time this study was conducted. Their age range was between 20-22 years old and none had overseas experience in any Chinese speaking countries. As L2 speakers of Mandarin, all participants had no history of hearing impairments or speech disorders at the time of the present study.

\subsection{Research Instruments}

Two instruments were employed in this study. The first instrument was a structured interview. The interview consisted of two major part. The first part was to have the participants arrange the tone hierarchy on the scale from the easiest tone to the most difficult one. The second part dealt with the reasons why one tone became the easiest or the most difficult one. The second instrument was a perception test, consisting of 100 questions to cover four Chinese tones (25 test stimuli in each tone). Since this study focused on tone perception, all 100 tokens were monosyllabic words without any context. All 100 questions representing 100 tokens shared the same answer choices (a. tone 1, b. tone 2, c. tone 3, and d. tone 4). A sample of the answer sheet is in Appendix A. It is very important to note that the objective for having the interview before the perception test was because the 
researchers intended to investigate the participants' genuine opinions about their tone performance. Otherwise, they might have some influence on the perception test.

\subsection{Research Validity and Reliability}

In terms of content validity, the researchers collected 120 monosyllabic words from a Chinese I textbook. Then, the selected tokens were presented in the form of the Item-Objective Congruence Index (IOC) to two Thai Chinese instructors who taught Chinese courses in a different university to examine the tokens as to whether they fitted the objectives of the study or not. The statistical results in each question by the two instructors were between $0.5-1.00$ which was in a suitable range for content validity. To ensure that the perception test questions were clear enough for the participants, a pilot project to examine the perception test was launched in summer 2014 with 10 students. After the pilot project the researchers made a few changes and finally only 100 tokens were employed in the present study.

\subsection{Data Collection and Procedure}

To elicit fresh and genuine learners' opinions about the four Chinese tones, the interview was launched and the perception test was provided later. Since all 14 participants were taking Chinese II with one member of the researcher team, individual interviews were arranged at their appropriate time in a quiet room. They were informed to be tape-recorded during the interview. One member of the researcher team acted as the interviewer and began the interview by asking a few general questions about their Chinese study to release some nervousness and pressure from the interviewees. Then, two major questions were asked. One was to have the interviewees arrange the tone hierarchy on the scale from the easiest tone to the most difficult one. Second, they were asked to provide reasons why a certain tone was so difficult or easy for them. Individual interviewees spent 5 minutes completing the session. After the interview, the researchers listened to the tape recorder and made notes of the interview. Two days later, a 100-question perception test was given to the participants. All participants took the test at the same time in a soundproof room. During the test time, in each question they listened to the stimuli produced by a native Chinese female speaker from a tape recorder. Each term was read twice. The pause between the first and second readings was 3-4 seconds. After the second reading, the participants had to identify the best tone from the answer sheet (a. tone $1, \mathrm{~b}$. tone 2 , c. tone 3 , and d. tone 4). They were informed not to skip any questions, listen to the tape only one time, and spend 10 minutes completing the test. After the test, the researchers collected the answer sheets and entered the participants' test scores on a computer program for the statistical analysis.

\section{Results}

To answer the first research question (Why do Thai university students perceive a certain tone better than others?), individual participants went through the structured interview in a quiet room with a tape recorder and a head-mounted microphone. As mentioned before, they were required to answer two major questions. One is "Could you arrange the tone on the scale from the easiest to the most difficult one?" The second question is "Why is tone $\mathrm{X}$ the easiest one, and why is tone $\mathrm{Y}$ the most difficult one?" Therefore, this part is divided into two subparts to fit the two interview questions

\subsection{Hierarchy of Tonal Accessibility}

When asked to arrange the tone accessibility from the easiest to the most difficult, most Thai participants $(9$ out of 14 or $64 \%$ ) claimed that tone 4 was the easiest one for them to produce and identify (see Appendix B for more details). Four students (or 29\%) stated that tone 1 was the easiest one; only one student (7\%) mentioned that tone 3 was the easiest one to produce. When asked to identify the second easiest tone, the answers were varied. That is, seven students (50\%) mentioned tone 1; 4 students $(29 \%)$ opted for tone 4 ; and three students $(21 \%)$ chose tone 2. In terms of the most difficult tone, 10 out of $14(71 \%)$ insisted that tone 3 was their major obstacle. 4 students (29\%) said that tone 2 was their most difficult tone. When asked to identify the second most difficult, the answers were varied. Seven students $(50 \%)$ opted for tone 2; three students $(21 \%)$ chose tone 3; three students $(21 \%)$ selected tone 1 ; and one student $(7 \%)$ identified tone 4 . To sum up their answers, Figure 2 reflects the hierarchy of tone accessibility from the interview.

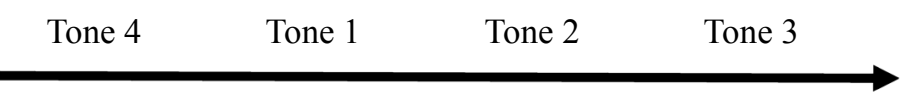

Figure 2. The Hierarchy of Tonal Accessibility (least difficult $\rightarrow$ most difficult) 


\subsection{Reasons behind Tonal Accessibility}

Most participants (64\%) confirmed that tone 4 was fairly clear-cut for them. For example, when producing it, they had to move their pitch abruptly from high to low. Or, when they listened to it, they could find the pitch change moving from a very high pitch to a very low pitch. The airstream mechanism was very sharp but short. Some reflected that this tone was a heavy one and the air was held for a few seconds before immediately releasing it. As mentioned earlier, 29\% claimed that tone 1 was the easiest tone. When they were asked to state the reason, the participants claimed that this tone did not require any air stream or energy to produce. The tone level was consistent, flat, and similar to the mid tone in their native language (Thai). Two participants stated that Tone 1 required the least amount of air o produce when compared to the other three Chinese tones. It was very similar to the normal air they used when speaking Thai.

In terms of tone difficulty, most participants (71\%) stated the tone 3 was their major obstacle. Most of the participants claimed that they were confused by tones 2 and 3 . They could not perceive the pitch contour difference between the two tones in that tone 2 had a sharp rise (35) and tone 3 started from a low level and the pitch went slightly deeper before going up (214). However, some realized that tone 3 required a longer pitch contour or the pitch went deeper and longer than tone 2. One participant stated that tone 3's pitch stayed in the throat; the sound did not come out from the mouth. Interestingly, one participant mentioned that $\mathrm{s} / \mathrm{h}$ was confused between tones 3 and 1 in the sense that the pitch went up and down, and had no confusion between tones 2 and 3 . In his/her opinion, tone 2 was easy since it was short and obvious.

To answer the second research question (To what extent can Thai university students perceive four Chinese Mandarin tones?), a quantitative data set is presented in the form of descriptive statistics as follows.

Table 1. Descriptive Statistics from the Perception Test

\begin{tabular}{cccccc}
\hline $\mathrm{N}=14$ & Min & Max & Sum & Mean (\%) & SD \\
\hline tone1 & 22.00 & 25.00 & 341.00 & $24.35(97.40)$ & 0.92 \\
tone2 & 18.00 & 25.00 & 300.00 & $21.42(85.68)$ & 2.34 \\
tone3 & 9.00 & 24.00 & 273.00 & $19.50(78.00)$ & 4.25 \\
tone4 & 24.00 & 25.00 & 349.00 & $24.92(99.68)$ & 0.26 \\
\hline
\end{tabular}

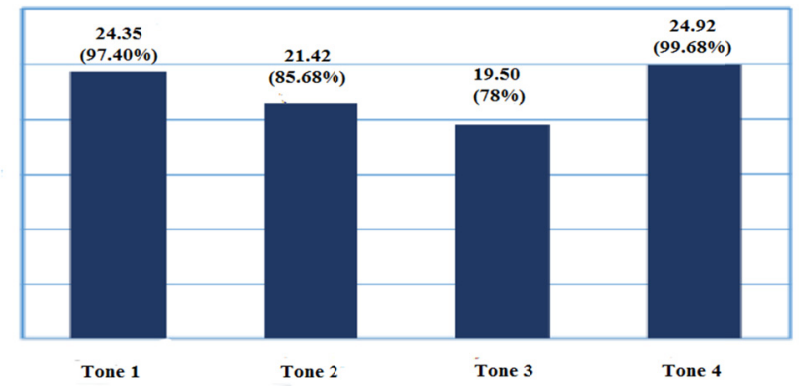

Figure 3. Perception Test Scores

In Table 1, Thai university students reveal an outstanding performance in tones 1 and 4 . To be more specific, they had an impressive performance in tone $4 ; 13$ out of 14 participants could achieve $100 \%$ accuracy in the test. The mean score was 24.92 out of 25 (or 99.68\%). More details are in Appendix C. In addition, its standard deviation (SD) was the lowest $(0.26)$. This reflects that the amount of variation or dispersion of a set of participants' scores was close to the mean score. In other words, the lower SD the group can show, the better performance the group has. Not surprisingly, its maximum and minimum scores were very close ( $\min 24$; $\max$ $25)$. Tone 1 also reveals another fantastic performance with a very high mean score $(24.35$ or $97.40 \%)$ and a very low SD (0.92). However, the participants' scores dropped in tones 2 and 3. In tone 2, the mean score was 21.42 (or $85.68 \%$ ). The gap between its maximum and minimum scores was wider ( $\min 18$; $\max 25)$; the SD (2.34) is more widespread than that in tones 1 and 4 . When compared to the other three tones, tone 3 reveals the poorest performance. The mean score was 19.50 (or 78\%). In addition, no participants identified the tones from the test $100 \%$ correctly; in other words, it was the only tone in which no perfect score from a single participant was found. The gap between maximum and minimum score was much wider $(\min 9 ; \max 24)$ with the highest SD 
(4.25). To draw a conclusion, the scale of mean scores and percentages in the four tones from the highest to the lowest was: tone 4 , tone1, tone 2 , and tone 3 , respectively. To visualize the participants' performance, Figure 3 is a bar chart to make a visual summary of the students' scores.

\section{Discussion}

When a qualitative data from the interview (to answer the first research question) was compared with a quantitative data from the perception test (to answer the second research question), both data sets were highly compatible. That is, tone 4 was the easiest one; tone 1 was the second easiest one; and tone 3 was the most difficult one; and tone 2 was the second most difficult one. The findings in the present study are congruent with those in Li's (2016) study (conducted in China), but they were different from the ones in Chen's (2012) study (conducted in Taiwan). In the latter study, tone 2 was the most difficult and tone 3 became the second most difficult. Tone 1 and tone 4 showed the highest and second highest scores, respectively. Therefore, Chen's hierarchy of tone accessibility from the least difficult to the most difficult one was tone $1>$ tone $4>$ tone $3>$ tone 2. Although the findings from Chen's study was different from those in $\mathrm{Li}$ (2016) and the present study, tones 2 and 3 demonstrated an uphill task for native Thai speakers. Below are the reasons behind tonal accessibility for Thai speakers.

Why were tone 1 , and particularly tone 4 easy for Thai participants to perceive? To answer this question, the tone contour and pitch level should be taken into account. Generally, tone 4 in Chinese is very similar to the falling tone in Thai. That is, in Chinese tone 4 the pitch level moves from high to low $(51 / \mathrm{HL})$, but in the connected speech the pitch might not drop down to the lowest as in a careful speech. In other words, the pitch range can be 52 or 53 (Lin, 2007). Either in careful or connected speech, the pitch level still goes from high to low. Likewise, the pitch in the Thai falling tone (or siăy $\mathrm{t}^{\mathrm{h}} \mathrm{ou}$ ) starts from the mid level and moves up and ends with a sudden fall (see Figure 4). Not surprisingly, in the interview session, a few Thai participants stated that they could perceive the pitch level moving from high to low in a sudden manner when dealing with tone 4 . Therefore, the Chinese tone 4, as a foreign lexical tone, was an obvious tone for Thai speakers to perceive for the pitch level reason. Mandarin Chinese tone 1 was another tone that Thais perceived well because it was similar to the mid tone in Thai. In general, tone 1's pitch level is 55 . It is a flat tone with a very high pitch level. The Thai mid tone has a slight fall all the way and moves up a bit at the end (see Figure 4). However, the pitch level in Thai is not as high as that in Chinese (see Figure 1). During the interview, the researcher also found that some participants mentioned that they had employed the Thai mid tone as a model when coping with Chinese tone 1.

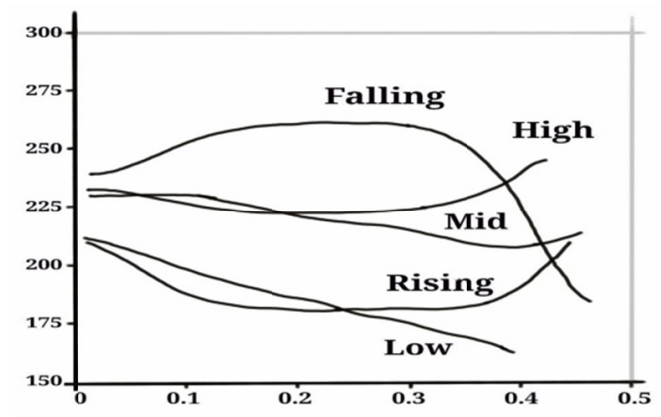

Figure 4. Thai Tones Recorded by Morén and Zsiga (2006, as quoted in Zsiga 2007).

Next, why was tone 3 the most difficult one for native Thai speakers? Many participants claimed that they were confused by tones 2 and 3. By and large, the confusion between these tones is not a very surprising phenomenon. The previous studies, particularly conducted with non-tonal speakers, namely native English speakers, shared the same results (Chen, 1997; Miracle, 1989; Tao and Guo, 2008, to name a few). Not only were native English speakers confused by tones 2 and 3, but they also struggled to deal with tones 1 and 4 . Unlike non-tonal language speakers, tonal language learners, such as native Thai speakers, still have some advantages in learning foreign lexical tones (Hallé et al., 2004; Wayland \& Guion, 2004; Winke 2007). In the present study, as mentioned earlier, Thai participants were not able to identify tone 2 from tone 3 well. Only a few participants stated that both tones were truly different. That is, tone 2 was a slightly shorter than tone 3 . We propose that the Thai rising tone (siăn jattawa) is very close to tone 3 in Chinese. Figure 5 shows that the contour shape from both Thai and Chinese tones look alike. Tone3's pitch direction moves deeper down than tone 2's. As a result, Thai speakers should have performed well in tone 3, but they had not done it well because of the confusion between tones 2 and 3. If Chinese had only either tone 2 or tone 3, Thai speakers would acquire it easily. In reality, Chinese tones 2 and 3 share certain common and different features. That is, both Chinese tones are 
contour tones. Tone 2 is a rising tone; tone 3 is a falling-rising or dipping tone (Chen, 2012). They share the rising pitch direction. However, tone 2 pitch does not go as deep down as tone 3 does. As a result, tone 2's pitch duration is shorter than the other. Most Thai participants might not perceive this difference well enough. The confusion fits the information from the interview session. That is, some participants claimed that both tones were very confusing for them to perceive and produce, and they were not able to distinguish one from the other.

Thai

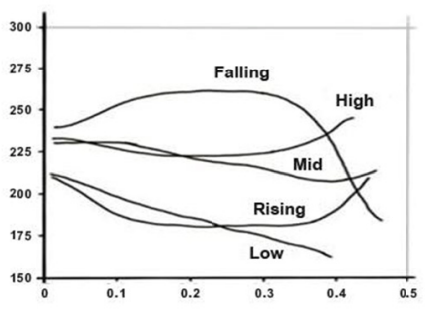

Chinese

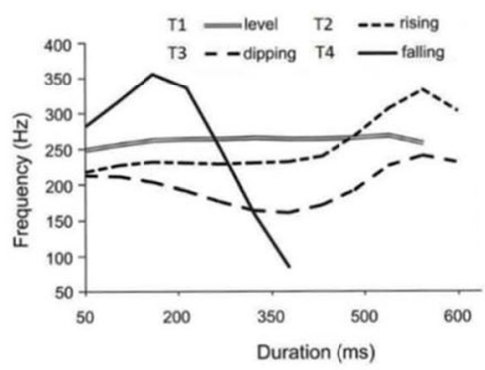

jangues

\subsection{Pedagogical Perspectives}

Even though Thai speakers perform well in tone 1 (level tone), the pitch level in Chinese tone 1 (55) is much higher than that in Thai mid tone. The instructors should pay special attention to this feature and emphasize these different pitch levels between the Thai mid tone and the Chinese tone 1 in the classroom. Tones 2 and 3 require a great deal of practice with time and energy to pronounce and perceive. Writing a diagram can be a helpful tool to visualize how a pitch movement or pitch level is made. For example, tone 2 starts from low level and has an immediate sharp rise. We agree with Cao (2002)'s suggestion that tone 3 can be represented by a tub or trough shaped diagram to implant the idea of the duration of the dip before the immediate rise. Tone 4 might not be a great concern since most Thai speakers perform it fairly well. Again, the Thai falling tone (sia $\mathrm{yt}$ ou) requires a bit longer time to produce as a contour tone. Thus, it is very close to Chinese tone 4 in the pitch direction from high to low level, but they are not the same tone. For one important reason, the Thai falling tone does not require as a sharp fall as Chinese tone 4 does. As a result, the attention can be paid to an immediate sharp fall to fit the pitch value 51 when the instructors have the students practice in classroom.

\section{Conclusion}

The present study investigated how native Thai speakers dealt with foreign lexical tones. Firstly, the interview was launched to gain in-depth information about their opinions on their Chinese tone performance. Later, the researchers employed the perception test to measure Thai participants' performance to examine whether the test scores were compatible with the findings from the interview or not. It can be summarized that both qualitative data (from the interview) and quantitative data (from the perception test) reveal that tone 4 outperformed the other three tones. For one important reason, tone 4 was very close to the falling tone in Thai. However, tone 3 became the most difficult one to perceive (and produce) even though it was similar to the rising tone in Thai, the participants were confused by Chinese tone 2 . To a certain extent, L1 or the mother tongue had a significant impact on acquiring foreign lexical tones, but it is not always the case. Since this study was conducted in Thailand, Chinese is regarded as a foreign language (CFL). The present findings, specifically the hierarchy of tonal accessibility, were close to those in Li's (2016) but rather different from those in Chen's (2012) even though both $\mathrm{Li}$ and Chen conducted their studies in native Chinese speaking countries (People's Republic of China and Taiwan, respectively) where Chinese was regarded as a second language (CSL) for non-Chinese speakers. As a result, more research studies on this issue particularly in Thailand or CFL contexts are still needed.

\subsection{Limitation and suggestions for future studies}

One of the major limitations in the present study is the number of participants. Generally, the larger number of participants in the research study, the more reliable the findings are. As a result, this study can be a stepping stone for Thai scholars to conduct more empirical research studies with a high number of participants in the future.

When students' performance in speech sounds is measured, both perception test and production test are 
employed. The present study did not have a test to examine a production performance to reflect students' pronunciation to confirm the findings. Thus, to paint the overall and complete picture of participant's performance on the four major Chinese Mandarin tones, the production test is highly recommended in future studies.

\section{Acknowledgments}

The research reported here has been fully supported by a grant from Division of Research Administration, Naresuan University, Thailand (a research project ID number: R2559C127) in the fiscal year 2016.

\section{Authors' contributions}

Apichai Rungruang had a primary responsibility for design and analysis of this study and drafted the manuscript. Yanhong Mu participated in data collection and analysis. Both authors read and approved the final manuscript.

\section{References}

Chen, Q. (1997). Toward a sequential approach for tonal error analysis. Journal of the Chinese Language Teachers Association, 32(1), 21-39.

Chen, C. (2012). Accuracy of Mandarin prosody in the production and perception of Thai learners. Foreign Language Learning and Teaching Journal, 1(2), 14-35.

Cao, W. (2002). Hanyu yuyin jiaocheng [A course of Chinese pronunciation]. Beijing: Beijing Yuyan wenhua daxue chubanshe.

Hallé, P., Chang, Y. \& Best, C. (2004). Identification and discrimination of Mandarin Chinese tones by Mandarin Chinese vs. French listeners. Journal of Phonetics, 32(3), 395-421.

Kwanrean, T. (2001). The comparison and contrast of Mandarin and Thai tones. MA Thesis. Yunnan Normal University, People's Republic of China. (in Chinese).

Lin, Y. (2007). The sounds of Chinese. Cambridge: Cambridge University Press.

Li, Y. (2016). English and Thai speakers' perception of Mandarin tones. English Language Teaching, 9(1), 122-132.

Tillmann, B., Burnham, D., Nguyen, S., Grimault, N., Gosselin N., \& Peretz, I. (2011). Congenital amusia (or tone-deafness) interferes with pitch processing in tone languages. Front Psycho. https://doi.org/10.3389/fpsyg.2011.00120

Miracle, W. (1989). Tone production of American students of Chinese: A preliminary acoustic study. Journal of the Chinese Language Teachers Association, 24(3), 49-65.

Masuntisuk, R. (2009). Chinese language teaching in Thailand at the primary and secondary education levels. Thai World Affairs Center, Chulalongkorn University, Thailand. Retrieved January 12, 2015 from http://www.thaiworld.org/upload/question/file_827.pdf

Tao, L. \& Guo, L. (2008). Learning Chinese Tones: A developmental account. Journal of the Chinese Language Teachers Association, 43(2), 17-46.

Theerawongseri, T (2009. Sino-Thai Cooperation in the Teaching and Learning of Chinese. Retrieved October 12, 2015 from http://www.thaiworld.org/en/include/answer_search.php?question_id=863

Wayland, R. \& Guion, S. (2004). Training English and Chinese listeners to perceive Thai tones: A preliminary report. Language Learning, 54(4), 681-712.

Winke, P. M. (2007). Tuning into tones: The effect of L1 background on L2 Chinese learners' tonal production. Journal of Chinese Language Teachers Association, 42(3), 21-55.

Xing, Z. (2006). Teaching and learning Chinese as a foreign language: a pedagogical grammar. Hong Kong: Hong Kong University Press.

Zsiga, E. (2007). Modeling diachronic change in the Thai tonal space. Paper presented at PLC31, University of Pennsylvania, Philadelphia. 


\section{Appendix A}

A sample of answer sheet

Name.

\begin{tabular}{|c|c|c|}
\hline 1. a. & b.' & c. $v$ \\
\hline 2. a. & b.' & c. ${ }^{v}$ \\
\hline 3. a. & b.' & c. ${ }^{v}$ \\
\hline 4. a. & b.' & c. $v$ \\
\hline
\end{tabular}

100. a.

b.

c. ${ }^{v}$

d. 、

\section{Appendix B}

\section{Hierarchy of Tonal Accessibility}

During the interviewing time, the individual participants were asked to arrange the tonal accessibility on the scale from the easiest to the most difficult one. The data set below answers the first research question (Why do Thai university students perceive a certain tone better than others?)

Participants $\quad$ Least difficult $\rightarrow$ most difficult

$\begin{array}{lllll}\text { S1 } & 4 & 1 & 3 & 2 \\ \text { S2 } & 4 & 2 & 1 & 3 \\ \text { S3 } & 1 & 4 & 3 & 2 \\ \text { S4 } & 1 & 2 & 4 & 3 \\ \text { S5 } & 4 & 1 & 2 & 3 \\ \text { S6 } & 4 & 2 & 1 & 3 \\ \text { S7 } & 4 & 1 & 2 & 3 \\ \text { S8 } & 3 & 4 & 1 & 2 \\ \text { S9 } & 1 & 4 & 2 & 3 \\ \text { S10 } & 1 & 4 & 2 & 3 \\ \text { S11 } & 4 & 1 & 2 & 3 \\ \text { S12 } & 4 & 1 & 2 & 3 \\ \text { S13 } & 4 & 1 & 2 & 3 \\ \text { S14 } & 4 & 1 & 3 & 2\end{array}$

\section{Appendix C}

\section{Perception test score report}

Scores from the perception test were employed to answer the second research question (To what extent can Thai university students perceive four Chinese Mandarin tones?). In the test, the proportion of questions in each tone was of 25 questions (100 questions in total).

$\begin{array}{lllll} & \text { Tone1 } & \text { Tone2 } & \text { Tone3 } & \text { Tone4 } \\ & (25 \mathrm{Q}) & (25 \mathrm{Q}) & (25 \mathrm{Q}) & (25 \mathrm{Q}) \\ \text { S1 } & 25.00 & 24.00 & 20.00 & 25.00 \\ \text { S2 } & 25.00 & 20.00 & 19.00 & 25.00 \\ \text { S3 } & 25.00 & 18.00 & 22.00 & 25.00 \\ \text { S4 } & 25.00 & 24.00 & 24.00 & 25.00\end{array}$




$\begin{array}{lllll}\text { S5 } & 24.00 & 22.00 & 23.00 & 25.00 \\ \text { S6 } & 24.00 & 21.00 & 19.00 & 25.00 \\ \text { S7 } & 24.00 & 24.00 & 15.00 & 25.00 \\ \text { S8 } & 24.00 & 19.00 & 15.00 & 25.00 \\ \text { S9 } & 22.00 & 20.00 & 9.00 & 25.00 \\ \text { S10 } & 25.00 & 20.00 & 24.00 & 25.00 \\ \text { S11 } & 23.00 & 24.00 & 18.00 & 25.00 \\ \text { S12 } & 25.00 & 19.00 & 20.00 & 25.00 \\ \text { S13 } & 25.00 & 25.00 & 24.00 & 25.00 \\ \text { S14 } & 25.00 & 20.00 & 21.00 & 24.00\end{array}$

\section{Copyrights}

Copyright for this article is retained by the author(s), with first publication rights granted to the journal.

This is an open-access article distributed under the terms and conditions of the Creative Commons Attribution license (http://creativecommons.org/licenses/by/4.0/). 